1 Universidade Federal Fluminense (UFF), Instituto de Saúde Coletiva (ISC) Niterói (RJ), Brasil. leandroapg@id.uff.br

2 Fundação Oswaldo Cruz (Fiocruz), Escola Nacional de Saúde Pública Sergio Arouca (Ensp) - Rio de Janeiro (RJ), Brasil.

3 Universidade Federal do Rio de Janeiro (UFRJ), Faculdade de Enfermagem e Obstetrícia - Macaé (RJ), Brasil.

\section{Saúde coletiva, colonialidade e subalternidades - uma (não) agenda?}

\section{Collective health, coloniality, and subalternities - an (absent) agenda?}

\author{
Leandro Augusto Pires Gonçalves' ${ }^{\mathbf{1}}$ Roberta Gondim de Oliveira², Ana Giselle dos Santos \\ Gadelha², Thamires Monteiro de Medeiros ${ }^{3}$
}

DOI: 10.1590/0103-11042019S812

RESUMO Neste ensaio, partimos da constatação que as instituições que compõem o campo da saúde coletiva encontram-se tensas pela entrada de ‘outros' corpos nos seus cenários. Corpos ‘outros' que questionam a organização institucional e a matriz que orienta o pensamento nesse campo de conhecimento. Em seguida, apresentamos as bases que sustentam essas instituições: a colonialidade, como uma matriz predatória que persiste e se reatualiza na contemporaneidade; e a modernidade, como um programa de pensamento que separa, determina e institui uma hierarquia civilizacional. Tais bases expressam-se no racismo e sexismo que estruturam o Estado nacional brasileiro e atravessam a ciência que fazemos e a saúde pública, com cujas práticas nos articulamos. Ponderamos que a saúde coletiva não escapa desse caráter estrutural brasileiro; para isso, discutiremos alguns problemas fundamentais do campo, que este tem demonstrado dificuldade de ver/reconhecer. Por fim, propomos às instituições que produzem a saúde coletiva cinco apostas que devem ser feitas para reconhecer e acolher esses corpos 'outros' que agora chegam ao ensino superior e têm urgência de contrapor discursos e práticas que historicamente os subalternizam e invisibilizam.

PALAVRAS-CHAVE Racismo. Saúde pública. Colonialismo. Colonialidade. Subalternidade. Necropolítica.

ABSTRACT In this essay we consider that the field of Collective Health in Brazil has been composed by new social actors in the last few years. From this statement, we propose that this change in composition has produced tensions in the Collective Health institutions, because this 'new actors' have questioned the matrix of thoughts that sustains this field of knowledge. Subsequently, we present the bases that support our institutions: coloniality, as a predactory matrix which re-updates itself in contemporaneity; and modernity, as a program of thought which separates, determines, and constitutes a civilizational hierarchy. We show that these bases express themselves through the racism and sexism that structures the Brazilian State, and consequently, composes science and public health and its practices. Considering that the field of Collective Health does not escape from this structural Brazilian character, we discuss some problems that such field has had difficulty to recognize. Finally, we point to the Collective Health institutions five proposals which contribute towards the reception of these 'new actors' in the field, as well as the discussions that they have brought up, which has been historically subordinate and unseen.

KEYWORDS Racism. Public Health. Colonialism. Coloniality. Subalternity. Necropolitics. 


\section{Para situar}

Falar em agenda na atual conjuntura soa pretensioso. E é. Pensar e projetar sobre o amanhã no mundo, no Brasil, em um movimento político como o da Reforma Sanitária e em um campo de produção de conhecimento como a saúde coletiva requer mais que resistir às forças predatórias que agora estão em evidência na cena política e institucional. É preciso disposição para a luta. Não lutaremos sem ter o que perseguir. Portanto, construir projetos e agendas que tenham a solidariedade e a luta contra a subalternização como pressupostos é tarefa importante, visto que não faltam por aí as que se fundam no indivíduo, na competição e na propriedade.

Ter a solidariedade e a não subalternização como pressupostos não nos traz garantias. Ambos são valores e práticas. Não se apagam as marcas de privilégio e de opressão pela mera disposição solidária, pois requer que estas sejam evidenciadas; com isso, nós também nos revelamos em nossas formas de estar no mundo e na maneira como o traduzimos. Se tais marcas estiverem em evidência, o caminhar para a solidariedade e a não subalternização será conflituoso. Qualquer projeto ou agenda que mire relações entre humanos mais simétricas e solidárias, e destes com o mundo, terá o conflito como prática e ética.

Hoje, as marcas de privilégio e opressão estão evidentes entre nós. Isso assusta, faz desesperar e traz desesperança. Ao mesmo tempo, é a hora de agir. Como lidar com tal paradoxo?

Se dizemos que as marcas de privilégio e opressão estão evidentes, usaremos o campo da saúde coletiva para as ilustrar. Nele, participamos e podemos dizer do que vivemos e sentimos. Vivemos e sentimos um campo, suas instituições, em tensão e conflito crescentes. Nelas, corpos que antes estavam em tarefas de 'serviço' começaram a entrar como estudantes dispostos a fazer docência e pesquisa. Corpos que têm se organizado em coletivos que já não são como as organizações estudantis de outros tempos. Esses corpos e coletivos têm denunciado e questionado com firmeza as dinâmicas de privilegiamento e opressão que as instituições de ensino superior reproduzem - dentre as quais as instituições do campo da saúde coletiva não escapam.

Consideramos que quatro fatores articulados provocaram a entrada desses corpos nos espaços acadêmicos da saúde coletiva e revelam o campo como não podíamos ter feito até aqui: o fortalecimento à participação de todas as profissões da saúde - a saúde coletiva é cada vez menos médico-centrada e tem, ainda, uma graduação própria; a expansão e a difusão do ensino universitário pelo País, fruto do Reuni (Reestruturação e Expansão das Universidades Federais); a expansão e a difusão pelo território nacional das pós-graduações, fruto das políticas de ciência e tecnologia; e a instituição das ações afirmativas nas instituições de nível superior, na graduação e na pós-graduação. Tais fatores articulados e coetâneos proporcionaram que corpos nunca admitidos, apenas na condição de exceção, entrassem em quantidade no ensino superior. Corpos femininos, negros, indígenas, não genderizados e periféricos entram em instituições que se referenciam como produtoras e validadoras do conhecimento humano interrogando-as sobre que humanidade vinha se levando em conta até aqui.

Já dissemos que as marcas de privilégio e opressão estão hoje mais evidentes. Este ensaio, além de sugerir a necessária produção de uma agenda para o campo, é um exercício de apresentação e registro de tais marcas. Ele é fruto da produção coletiva, da experiência de quatro corpos inseridos na saúde coletiva, corpos muito diferentes entre si: somos quatro autores que temos diferentes vínculos institucionais e diferentes trajetórias; somos duas mulheres negras, uma nortista e outra nordestina, e uma mulher e um homem brancos sudestinos, cariocas e suburbanos. Podemos dizer: o que trazemos aqui é um exercício produzido a oito mãos, não necessariamente sem conflito, e que não expressa as nossas 'vozes' como um coro harmônico. A síntese 
que trazemos foi o exercício de falar sobre, suportar e tornar a inquietação colonial que nos constitui em algo produtivo. Consideramos que torná-lo visível é fundamental para que tratemos da reparação e da recuperação política e afetiva que suscita.

Nas próximas páginas, diremos sobre as estruturas que garantem, até aqui, a produção de marcas que privilegiam e oprimem determinados corpos. São estruturas éticas, políticas, cognitivas e materiais que fundam nossas instituições brasileiras. Apesar de marcarem corpos no nível local - em realidades concretas, representam estruturas que emanam de longe, de outros territórios que o Brasil, e dão forma a uma rede de relações e instituições que se dispõem ao 'global'.

Como falaremos de instituições da saúde coletiva e de produções de marcas nesses lugares, argumentamos que a colonialidade dá o tom racista e sexista, garantido no período moderno, que também compõem a base de sustentação da ciência que fazemos e as maneiras como atuamos técnica e politicamente. É duro e parece precipitado quando lemos esse argumento assim escrito em uma frase, especialmente em um campo que se apresenta interdisciplinar e plural, mas veremos como essas estruturas produzem a saúde coletiva e como esta tem privilegiado certos corpos e sido pouco sensível a certos temas.

\section{Sobre as nossas bases: a colonialidade}

O Brasil deixou de ser colônia, oficialmente, em 1808, quando tornou-se sede do império português. Isto não quer dizer que tenhamos superado os nossos primeiros 300 anos de colonização. O termo colonialidade se refere a uma matriz ética, política, cognitiva e material predatória sobre a qual se erguem diferentes formas institucionais ao longo do tempo. A colonialidade não depende da existência de colônias: ela se reatualiza permanentemente, produzindo novos arranjos institucionais e formas de expropriar, dividir, subalternizar e invisibilizar grupos, incorporando e intensificando graus de opressão'

Enquanto matriz, a colonialidade se instaura no projeto colonial europeu. Por isso, precisamos dizer, mesmo que brevemente, algo sobre os eventos coloniais que se deram a partir do final do século XV. Foi o momento em que os modos de viver, ver e produzir europeus foram projetados para outros territórios enquanto norma, constituindo a relação metrópole-colônia. Tal projeção partia do entendimento dos territórios das colônias como espaços do 'não ser'2, dos 'não humanos' e da não propriedade e, portanto, da total exploração e liberdade. Os próprios 'conquistadores' foram os avalizadores da sua permissão e possibilidades.

Entre as 'descobertas' das 'grandes navegações’ e o século XVIII, instalou-se a projeção europeia nos territórios coloniais. Foi o tempo de inventariar o espaço, os povos, os recursos naturais e operar a sua expropriação $0^{3}$. Houve também, e fundamentalmente, o sequestro e trânsito de povos de outros territórios para povoar as colônias e para serem explorados como propriedade dos colonizadores, como na escravidão. Foi o tempo de instalar aqui as bases de representação, aqueles 'humanos' e grupos que seguiriam tornando o 'novo mundo' a extensão da Europa - os brancos, e, com alguma possibilidade maior ou menor, os 'criollo' aderidos à metrópole, a depender da colônia".

O século XVIII, aquele considerado como o 'das Luzes', trouxe novidades, perturbação e aprofundamento ao projeto colonial. A consolidação dos Estados-nação europeus desde o século XVII, as revoluções americana, francesa, a haitiana - uma revolução protagonizada por escravos de origem no continente africano, combatida pelas outras nações, especialmente a França ${ }^{5}$ - e a industrial6, ainda que com diferentes impactos e repercussões, ofereceram novos contornos as relações entre metrópole e colônia: não apenas extensão de Estados-nação europeus, 
as colônias passaram a buscar o próprio status de Estado-nação. Essa reivindicação produziu o surgimento de inúmeros Estados-nacionais nas Américas no final do século XVIII e início do XIX, o que, entretanto, não representou menor subjugação ${ }^{4}$. Ao contrário, houve o alinhamento de tais Estados a uma economia capitalista mundializada, na qual a estrutura estatal, nacional, industrial e extrativa de matérias primas seria a tônica ${ }^{7}$. Ainda que não fossem mais formalmente colônias, a colonialidade como matriz seguia preservada: os Estados que antes foram metrópoles seguiram sendo o 'norte' para os Estados nacionais que antes foram colônias.

Entre os povos colonizados, como no Haiti, houve aqueles que lutaram e apontaram a ruptura com o padrão de exploração colonial. Essas lutas têm sido permanentemente invisibilizadas nas histórias oficiais das nações. Um exemplo brasileiro disso é o sumiço das jihads malês, na Salvador do início do século XIX, do imaginário nacional até tempo recente ${ }^{\mathbf{8}, 9}$. A colonialidade se expressa fundamentalmente no exercício permanente de se fazer esquecer para permanecer e explorar. Entre os Estados nascidos no século XIX, a nação brasileira se constrói sobre esta matriz. Nossas instituições estão atravessadas por expressões dela.

\section{A operação do pensamento: modernidade, razão e a formalização das diferenças}

Como dito, o 'século das luzes' ofereceu novas e 'eficientes' ferramentas de pensamento para o aprofundamento da exploração e expropriação de territórios antes coloniais. Foi nesse período que filósofos como Immanuel Kant (1724 - 1804) e Friedrich Hegel (1770-1831) muito contribuíram para dar forma ao que chamamos de modernidade. Como define Denise Ferreira da Silva ${ }^{10}$, a modernidade trata-se de um programa de pensamento construído e aperfeiçoado desde o século XVI que tem na virada dos séculos XVIII e XIX o seu apogeu. Um programa de pensamento que se baseia nas noções de 'separabilidade, determinabilidade e sequencialidade'10, noções que seguem operando desde os nossos pressupostos éticos, políticos, econômicos e epistemológicos contemporâneos.

Kant estabeleceu que 'tudo o que pode ser conhecido sobre as coisas do mundo está compreendido pelas formas (espaço e tempo) da intuição e as categorias do Entendimento (quantidade, qualidade, relação, modalidade)'10(60).

Assim, tudo o que esteja fora do espaço, definido por critérios geométricos, do tempo, definido por critérios cronológicos, e das categorias do entendimento estão fora, não participam daquilo que é humano e universal, visto que não são acessíveis ao próprio humano; esta é a noção de 'separabilidade'. Como consequência disso, o conhecimento humano resultaria

[...] da capacidade do entendimento de produzir constructos formais, que ele pode usar para determinar (isto é, decidir) a verdadeira natureza das impressões sensíveis compreendidas pelas formas da intuição(10(60).

Esta é a noção de 'determinabilidade'10. Com Kant, o homem - aqui usamos homem de maneira proposital - europeu, moderno e universal passa a ser capaz de definir o que está fora, excluído da perspectiva humana, e classificar o que está dentro conforme categorias formais e, portanto, verificáveis.

Hegel ${ }^{10}$, um pouco mais à frente no tempo, operou a entrada do espírito nesse programa de pensamento tão formal, como formulado por Kant. Para ser efetivamente universal, o programa - ou sistema, como é comum usar - deve incorporar uma dimensão de sentido. Um sistema de pensamento humanista deveria ser capaz de oferecer respostas às questões fundamentais da existência, a 
saber: 'quem somos?', 'de onde viemos?', 'para onde vamos?'. Para isso, na sua 'Fenomenologia do Espírito'10, Hegel "descreve o Espírito como movimento no tempo, um processo de autodesenvolvimento, e a História como a trajetória do Espírito"10(60); esta é a 'sequencialidade'10. Com esse aperfeiçoamento hegeliano, que inclui a transformação por meio do movimento histórico e dialético, o homem moderno e europeu passou a ser capaz de dizer o que é e não é humano, a classificar as coisas humanas e a atribuir um padrão de evolução às coisas humanas, sem a interferência divina. Este sistema de pensamento passou a dar legitimidade a toda estrutura institucional a qual estamos acostumados, no plano ético, epistemológico, jurídico, político e econômico. Justificará desde os Estados-nação, e a sua secularização, até a escravidão; desde a indústria até as plantations; desde o que é público até o que é privado.

Tal programa moderno e iluminista, curiosamente, foi formulado no centro geográfico da Europa, onde hoje é a Alemanha ${ }^{11}$. O mesmo território onde se deram as tratativas que resultaram na 'paz de Vestfália', evento considerado pelos historiadores e cientistas sociais como o marco para a emergência e consolidação dos Estados-nacionais europeus no século XVII ${ }^{12}$. Para Silva ${ }^{10}$, é esse programa que serviu como pressuposto para a concretização da Europa, de seus Estados-nacionais, povos e corpos como medida de todas as coisas, pois haveria

[...] uma conformação temporal da diferença cultural como realização de momentos distintos do desenvolvimento do Espírito, cujo ápice seria representado pelas configurações sociais europeias pós-iluministas ${ }^{\mathbf{1 0}(60)}$.

Isso é o que significa sermos um Estado nacional moderno de origem colonial. Agora veremos como essa organização institucional e de pensamento tem operado sobre os nossos corpos.

\section{As clivagens que somos: raça, sexo/gênero e outras marcas em produção}

O programa moderno e exclusivo europeu produziu clivagens importantes sobre os corpos e territórios aonde aportou. Intelectuais contemporâneas ${ }^{13-15}$ apontam as marcas sociais produzidas desde o período colonial que seguem se reproduzindo em diferença e exclusão de corpos, povos e territórios. Maria Lugones ${ }^{\mathbf{1 4}}$ apresenta a noção de 'colonialidade de gênero', afirmando que a clivagem fundamental, produzida no evento colonial, é a que se estabelece entre humanos e não humanos, sobre a qual se opera a clivagem de gênero:

[...] uma distinção dicotômica, hierárquica entre humano e não humano foi imposta sobre os/as colonizados/as a serviço do homem ocidental. Ela veio acompanhada por outras distinções hierárquicas dicotômicas, incluindo aquela entre homens e mulheres. Essa distinção tornou-se a marca do humano e a marca da civilização. Só os civilizados são homens ou mulheres. Os povos indígenas das Américas e os/as africanos/as escravizados/as eram classificados/as como espécies não humanas - como animais, incontrolavelmente sexuais e selvagens ${ }^{14(936)}$.

Nessa produção de distinção e dicotomias pelo homem europeu - que é o humano padrão no imaginário colonial e moderno -, outro desdobramento é a classificação social das populações do mundo mediante a noção de raça. Raça, uma categoria política, difunde-se nas teias das relações entre metrópoles e colônias produzindo a classificação daqueles que não eram vistos como humanos. Tal noção é o eixo que orienta as formas de sociabilidade e de subjetivação, os modos de estar no mundo, e é expressão do domínio colonial, da racionalidade e do poder europeus. Raça, portanto,

[...] sustenta-se na imposição de uma classificação racial/étnica da população do mundo 
como pedra angular do referido padrão de poder e opera em diversos planos, [tanto] materiais e [como] subjetivos ${ }^{\mathbf{1 ( 8 4 )}}$.

É nesse movimento que se entende raça como um derivativo do racismo, enquanto produção discursiva e material, e não o contrário ${ }^{\mathbf{1 6}}$.

O racismo enquanto expressão da colonialidade e substrato da 'racialização' instaura um padrão de sociabilidade e das subjetividades, estabelecendo novo universo de relações. A construção de identidade pela negativa da humanidade, pela subalternização e invisibilização de sujeitos, encobre, limita e extermina formas de estar no mundo ${ }^{2}$. Esse universo, material e intersubjetivo, elabora, formaliza e institucionaliza modos de ordenação social e, no caso de interesse deste ensaio, a produção de conhecimentos que fornecem as bases de controle, medição e ordenação de vidas humanas, que objetificam corpos.

\section{A ciência que temos}

Demos visibilidade a algumas clivagens que consideramos estruturantes da 'nacionalidade brasileira', como o sexismo e o racismo ${ }^{17,18}$. Além dessas, há outras mais sutis também operadas no cotidiano institucional, que, às vezes, ganham a legitimidade por estarem imbuídas de um sentido prático e necessário: educar e cuidar por exemplo. A biomedicina, que especialmente nos diz respeito e estrutura epistemologicamente nosso campo e áreas atuação, é parte constitutiva da ciência ocidental moderna ${ }^{19}$, que se beneficiou, e parte dela segue se beneficiando, de experimentações de base colonial. A biomedicina é indissociável da conformação da ciência e do Estado moderno europeus, seja através produção de saberes, da manutenção da força de trabalho e do processo de colonização (expropriação de sujeitos, culturas e territórios) ${ }^{20}$. A hegemonia da razão moderna sobre as demais epistemologias se dá pela emergência de uma concepção a-histórica do processo de construção do conhecimento cientifico e do apagamento e subalternização das demais formas de conhecimento - o epistemicídio - que inferioriza ou mesmo destrói demais formas de saberes em nome do processo de dominação e da produção de verdades ${ }^{\mathbf{2 1}}$.

Reconhecemos a relevância do papel das tecnologias biomédicas e sua tradução em dispositivos de saúde pública. Entretanto, esse reconhecimento não impede o alerta sobre os efeitos de sua 'portabilidade' para territórios outros e transposição no tratamento de corpos como objetos, sendo matriz de controle sobre populações. Além disso, a sua eficácia está atrelada a todo o conjunto garantido pela cosmologia moderna, que formaliza instrumentos para a sua própria legitimação.

Concluindo esta sessão, retomamos a saúde coletiva para situá-la. Trata-se de um campo de produção de conhecimento sobre a saúde, que tem a ciência moderna como forma de conhecer e forte articulação com os dispositivos de saúde pública. Esse campo é constituído por instituições de ensino superior que são parte do Estado brasileiro, que é forjado à luz do modelo colonial da modernidade eurocêntrica, ou seja, que tem a colonialidade como matriz. É um campo em que questionamentos sobre o caráter extrativista das instituições estatais, e de seus agentes, emergem eventualmente ${ }^{22}$. Contudo, veremos que esse campo desconsidera muitas questões fundamentais, haja vista sua situação e ferramentas de leitura do mundo.

\section{Alguns problemas de hoje que a saúde coletiva tem dificuldades de reconhecer}

\footnotetext{
O alagoano J.S, 21, infelizmente tinha contra si dois fatores. Era jovem e negro. Em seu estado isso significa que ele tinha as mesmas chances de ser assassinado do que se morasse em El Salvador, um dos países mais violentos do mundo com uma taxa de homicídio de 60 mortos por 100.000 habitantes. Terminou
} 
baleado caído na calçada no bairro Chã da Jaqueira, periferia de Maceió. Destino diferente teve P. H. Z., 27. Apesar da pouca idade, o conterrâneo de Silva foi aprovado em concurso para ser diplomata pelo Itamaraty. Assim como Silva, ele é alagoano. Mas com uma diferença: a cor de sua pele é branca. Para um homem branco em Alagoas, as chances de ser morto são baixíssimas, as mesmas dos Estados Unidos: 5,3 homicídios por 100.000 habitantes. A Organização Mundial de Saúde considera epidêmicas taxas acima de $10^{\mathbf{2 3}}$.

Desde a década de 1960, o Brasil tem passado por intensas mudanças, muitas delas lideradas pelo governo ditatorial civil-mili$\operatorname{tar}$ (1964-1985) nos seus planos econômicos e sociais ${ }^{24}$. São mudanças importantes que visam manter a Ordem e o Progresso, como sempre; ou seja, mudanças para manter-se tudo como sempre foi quanto ao estamento social. Naquela década, o País iniciava um processo avassalador de urbanização, intensificado especialmente no período de exceção política. Era um tempo em que a dicotomia entre um Brasil urbano e outro rural ainda fazia sentido, em que a fome se localizava especialmente na área rural 25 - ainda que Carolina Maria de Jesus ${ }^{26}$ já tivesse registrado a miséria e a fome urbana em seus diários.

Hoje, o País tem uma teia urbana e agrícola que cobre praticamente todo o território; cerca de $80 \%$ da nossa população vive em cidades, e as metrópoles urbanas tornaram-se o espaço de acolhimento e 'gestão' da miséria. Milton Santos ${ }^{25}$ nos apontou esses fenômenos no início da década de 1990, os quais se intensificaram e radicalizaram desde a contribuição do geógrafo. Hoje, o território brasileiro está em boa parte informatizado, por isso atualizado permanentemente na escala geopolítica 'global' (ou seja, do capital); nossas cidades tornaram-se corporativas; nossos campos, industriais; e a capacidade extrativa sobre o nosso território tornou-se praticamente total. Não éà toa que a Amazônia se torna hoje como o centro de interesse do mundo, por ser floresta que é barreira a tal capacidade extrativa ${ }^{27}$.
Ainda que a forma, a intensidade e a massividade sejam diferenciadas, quando dizemos que o Brasil permanece em Ordem e Progresso é porque os nossos problemas estruturais são os mesmos de séculos: racismo e sexismo estruturais, com a produção genocida sistemática sobre aquela população considerada fora do padrão de humanidade ou cidadania $\mathbf{1 7 , 1 8 , 2 8 , 2 9}$. Nosso estado mata como sempre, tanto como nunca. Não houve constituição cidadã que tenha mudado esse estado de coisas. O 'Atlas da violência $2018^{\prime 29}$ deu visibilidade e tom enfático à tragédia nacional: cerca de 60 mil mortes violentas em 2016, cerca de 500 mil mortes na última década. Tais números de guerra tornam-se ainda mais cruéis se levarmos em consideração detalhes tão fundamentais quanto profundamente ancorados na colonialidade:

Outra questão que já abordamos em outras edições do Atlas da Violência é a desigualdade das mortes violentas por raça/cor, que 'veio se acentuando nos últimos dez anos' (grifos nossos), quando a taxa de homicídios de indivíduos não negros diminuiu 6,8\%, ao passo que a taxa de vitimização da população negra aumentou 23,1\%. Assim, em 2016, enquanto se observou uma taxa de homicídio para a população negra de 40,2, o mesmo indicador para o resto da população foi de 16, 0 que implica dizer que $71,5 \%$ das pessoas que são assassinadas a cada ano no país são pretas ou pardas $29(4)$.

Diante de tamanha contundência, propomos a aproximação entre Milton Santos ${ }^{25}$ e Achille Mbembe ${ }^{30}$ para refletirmos sobre as atualizações da colonialidade no Brasil. Apostamos nesse diálogo para falarmos das nossas metrópoles, ou melhor, necrópoles. As nossas 'cidades corporativas' 25 tratam de maneira corporativa a pobreza: produzem verdadeiras zonas de exclusão, de morte, em que a exceção política e legal é a própria ordem: as zonas do 'não ser'2,31. 
Por 'cidades corporativas', Milton Santos 25 entende aquelas cujo processo de urbanização é empreendido por meio dos interesses das grandes empresas transnacionais, oligopólios que procuram dar a direção e o tom das instituições no atual capitalismo de face monopolista e financeira. Tendo a 'ideologia do crescimento' como força motriz, tal comando se exerce por intermédio da modernização urbana que se dá por uma operação racional e tecnológica que garante resultados contraditórios e concomitantes: geram-se riquezas de modo extraordinário, cada vez mais concentradas, produz-se pobreza, cada vez mais difundida, enquanto surgem novas classes médias. Classes médias que são

[...] indispensáveis à operação do sistema, na cidade e no campo, onde se instalam como nervo e instrumento da circulação e como alavanca de uma produção e de um consumo hegemônicos, isto é, comandado pelas corporações 25(104).

Essas cidades são receptáculos

[...] das consequências de uma expansão capitalista devorante dos recursos públicos, uma vez que estes são orientados para os investimentos econômicos, em detrimento dos gastos sociais ${ }^{25(95)}$.

As metrópoles assim produzidas na contemporaneidade ocupam superfícies imensas que, contraditoriamente, contêm verdadeiros vazios; sua organização tem o modelo rodoviário como forma de transporte, permanente carência infraestrutural e lógica especulativa sobre terras e propriedades imobiliárias, o que provoca

extroversão e periferização da população, gerando, graças às dimensões da pobreza e ao seu componente geográfico, um modelo específico de centro-periferia25(95).

Cidades atravessadas por uma lógica especulativa, nelas criam-se sítios sociais uma vez que o funcionamento da sociedade urbana transforma seletivamente os lugares, afeiçoando-os às suas exigências funcionais ${ }^{25(96)}$.

Desse modo, certos pontos mais acessíveis e com maiores recursos tecnológicos e estruturais são valorizados; neles se instalam as dinâmicas atividades econômicas e residem as pessoas com recursos financeiros e que têm capacidade de consumo. Cria-se algo como duas cidades no território urbano: uma 'cidade econômica'25, que procura sugar todos os recursos coletivos, e outra 'cidade social'25, que se organiza como o espólio da primeira. Essa dinâmica territorial e predatória produz formas de sociabilidade que se caracterizam por interesses exclusivos de grupos, seja no seu exercício ativo, pelos que são privilegiados pela dinâmica, seja no exercício da resistência pelos que mais sofrem com ela.

Nas palavras do geógrafo brasileiro:

[...] a cidade atual presta-se a recriação desse tipo de segmentação, com a emergência de grupos mais ou menos organizados, lutando de maneira difusa ou com o apoio de lobbies mais ou menos agressivos e mais ou menos aparelhados, através de discursos, marketing, alianças duráveis ou colusões ocasionais, estratégias e táticas pela prevalência de suas reivindicações setoriais. São interesses de classes de categorias profissionais, de bairros, de tipos de proprietários, como os donos de automóveis, mas também de grupos étnicos, de gênero ou de comportamento sexual que buscam a construção de sua identidade, mas também o discurso de suas reclamações particulares e a melhor prática para sua militância, destinada a obter, no plano jurídico ou material, compensações e vantagens ${ }^{25(109)}$.

Quanto aos vazios urbanos indicados por Milton Santos, Achille Mbembe ${ }^{30}$ contribui para o entendimento desses territórios de exclusão com a noção de 'necropolítica', que reapresenta a noção de biopolítica ${ }^{32}$ não 
apenas nas vertentes de controle, do 'fazer viver' ou do 'deixar morrer'. Mbembe traz ao debate a política da morte impetrada pelo Estado, em diferentes registros como o social e o biológico, tanto no quadro colonial moderno como também em sua face contemporânea ${ }^{33}$. A importância da noção de necropolítica reside na denúncia e inteligibilidade em relação ao modelo político de exceção, do Estado de guerra, que normaliza o terror e o 'assassínio direto'. Mbembe aporta a necropolítica em três registros, assim propostos:

Primero, referirme a aquellos contextos en que lo que comúnmente tomamos como el estado de excepción se ha vuelto lo normal, o al menos ya no es la excepción. La excepción se ha vuelto lo normal [...]. Segundo, lo usaba para referirme a aquellas figuras de la soberanía cuyo proyecto central es la instrumentalización generalizada de la existência humana, y la destrucción material de los cuerpos y poblaciones humanas juzgados como desechables o superfluos. Y también lo usé para referirme, como el tercer elemento, a aquellas figuras de la soberanía en las cuales el poder, o el gobierno, se refieren o apelan de manera continua a la emergencia, y a una noción ficcionalizada o fantasmática del enemigo30(135-136).

O filósofo camaronês fala sobre as formas em que o Estado de exceção opera no registro de guerra, convertendo-a em "base normativa do direito de matar", construindo uma ideia "ficcional de inimigo"30(21). Usando exemplos atuais, como da guerra do Afeganistão após o '11 de setembro', ressalta que a emergência do terror moderno tem como primeiras experimentações 'biopolíticas' a escravidão e o colonialismo, tendo na demarcação racial, na diferenciação biológica e 'cultural', referências para a negação do reconhecimento da 'humanidade' do 'outro'. Refere-se às ‘ocupações coloniais tardias', como o caso palestino, em que no processo de apropriação territorial os 'dispositivos infra estruturais' desempenham papel estratégico de biopoder no modo do necropoder: destruição de casas; cerceamento do acesso a água, iluminação e estradas; utilização de aparatos de guerra (tanques, helicópteros e drones).

Tal como a estratégia de 'guerra às drogas' posta em marcha nas favelas do Rio de Janeiro: 'incursão policial', 'guerra às drogas', 'bala perdida', 'traficantes de drogas' são alguns dos termos utilizados como parte na construção de uma narrativa que procura naturalizar o regime de exceção operante na cidade do Rio de Janeiro. A política de segurança pública, por meio da narrativa ficcional do 'combate ao tráfico de drogas', seleciona o locus de sua ação: as favelas, locais em que os dispositivos necropolíticos operam de forma similar ao território palestino. Tiroteios são cotidianizados e domesticados, assim como as mortes provocadas. As favelas, que são espaços urbanos com a maior concentração de pessoas negras, tornaram-se os inimigos ficcionais do restante da cidade, sendo seu extermínio justificado para que se garanta a segurança daqueles que vivem fora desses territórios. Essas mortes são legitimadas e inseridas no registro da emergência e da exceção.

Talvez demais entorpecidos pela verve cidadanizadora da Constituição de 88 , especialmente no seu capítulo da Saúde - que previa o direito social e universal à Saúde -, tenhamos tido dificuldade de perceber que, nas últimas cinco décadas, o Estado brasileiro produziu formas muito sofisticadas de operar a exceção jurídica em territórios e corpos marcados, mantendo grandes contingentes populacionais à margem dos direitos fundamentais contidos na nossa Carta Magna.

\section{O genocídio que a saúde coletiva não percebe}

O racismo é uma ferida que não se cura soprando, é preciso tocar nela profundamente. 
E isto dói. Sempre houve dor pro sujeito negro. Não pode ser mortal o desconforto e a dor no sujeito branco. Mas a branquitude é um 'tumor' que deve ser socialmente extraído, junto com o racismo. Não haverá fim do racismo sem o fim da branquitude. Aviso, mesmo não achando necessário: fim da branquitude não tem nada a ver com fim das pessoas brancas. Tá dito. A branquitude é um tumor no corpo social porque, entre outras razões, no seu predomínio por séculos e séculos, a branquitude (sobretudo os produtores brancos de saber) perderam a noção de privilégios que sempre possuíram ou sabem que estes privilégios perceptivelmente existem mas insistem em dissimula-lo, negando sua existência total ${ }^{\mathbf{3 4}}$.

É importante relacionarmos a alta incidência de mortes de jovens negros nas favelas 35 à noção de necropolítica e do racismo; relacionarmos, também, a pouca atenção que damos, na área da saúde, inclusa a saúde coletiva, à saúde da mulher negra, como denunciado por Jurema Werneck ${ }^{36}$. Ao fazermos esse movimento, queremos trazer à tona questões historicamente invisibilizadas, como os debates protagonizados pelo Movimento Negro e o Movimento de Mulheres Negras ${ }^{\mathbf{3 7}, 38}$. Nestes, lutou-se pela implementação de políticas de ações afirmativas, o que gerou intenso debate público sobre o mito da democracia racial, a pedra fundamental do racismo à brasileira ${ }^{\mathbf{1 7}, 39}$. À época, no início dos anos 2000, em que se discutia sobre a criação do Estatuto da Igualdade Racial, a mídia impressa assim como diversos intelectuais - um grupo deles publicou um 'Manifesto Contra as Cotas' $\mathbf{4 0}$ - denunciaram a perigosa divisão racial que estaria sendo provocada no Brasil41. Na arena da Saúde, previamente a publicação da Política Nacional de Saúde Integral da População Negra ${ }^{42}$, publicação garantida pelos esforços de militantes e acadêmicos do Movimento Negro ${ }^{35,43}$, também houve tensões relacionadas com essa discussão. Ferreira ${ }^{\mathbf{4 4}}$ indica, em seu estudo, os discursos contrários à adoção de políticas de ações afirmativas na saúde, entre os quais se notabiliza o artigo 'O SUS é racista?'45, uma denúncia, feita por autores brancos, da suposta racialização da luta pela saúde no Brasil.

Em um outro sentido, como estratégia de fomentar pesquisas que discutam o racismo e incentivem a inclusão do recorte racial no campo da saúde coletiva, foi proposta a criação, em 2003, do Grupo de Trabalho Racismo e Saúde da Abrasco (Associação Brasileira de Saúde Coletiva) ${ }^{\mathbf{4 6}}$. Entretanto, este GT foi formalizado apenas em 201747 , informação que nos leva a questionar: que conjuntura provocou que um GT voltado a discutir racismo levasse 14 anos para ser oficializado? Nesse tempo, os currículos de formação em saúde têm incluído ou reforçado a invisibilidade de narrativas de (re)existência de comunidades indígenas, quilombolas, negras, LGBTQI+? O quanto houve de esforço, avanço e aprofundamento de debate no campo da saúde coletiva no que diz respeito às pesquisas que reflitam sobre as condições de vida de populações historicamente vulnerabilizadas, como a população negra? Reconhecendo a influência desse campo para a construção de políticas e contornos de ações do SUS, retomamos o questionamento de Faustino ${ }^{\mathbf{4 8 ( 9 7 )} \text { : }}$ "até que ponto o SUS tem utilizado os dados de saúde desagregados por raça/cor para criar ações, definir políticas e prioridades para a promoção da equidade?”. Para além de análises dessa natureza, de base categoriais, também são pouco frequentes estudos que se dediquem a desvelar dinâmicas pelas quais o racismo opera e que resultam em desfechos desfavoráveis às pessoas negras.

As tensões e os conflitos gerados em torno da questão racial podem nos apontar a um estranhamento da realidade social brasileira: como, em um país com dados alarmantes quanto às desigualdades raciais, nega-se o racismo estrutural e nega-se a necessidade de reparação? Negam-se e 
naturalizam-se as desigualdades raciais, que, apesar de escancaradas na cotidianidade das relações sociais, tornam-se 'invisíveis'; tão invisíveis quanto a racialidade branca. Os povos brancos forjaram a noção de raça, mas nunca a aplicaram a si mesmos, dado que a própria noção se fez para marcar o corpo do outro, para sequestrar humanidade do outro. Assim, o branco não é raça, mas a norma, o corpo universal ${ }^{\mathbf{3 4}}$. $\mathrm{O}$ mundo ordenado pelo privilégio branco é a normalidade, de tal forma que os privilégios não são sequer percebidos como tal. Nessa configuração, os grupos brancos que pautam a negação de medidas de reparação aos povos racializados usam ideais de universalidade e de direitos iguais; usam, para se justificar, frases do tipo: 'independente de cor, somos todos humanos'.

Esta é a postura cínica da branquitude: argumentam que ações de reparação aos povos oprimidos historicamente seria equivalente a produção de desigualdades e privilégios, como se essa produção já não estivesse sido historicamente estruturada pela própria branquitude.

\section{O que será do amanhã?}

[...] ao invés de fazer a usual pergunta moral: 'Eu sou racista?' e esperar uma resposta confortável, o sujeito branco deveria perguntar-se: 'Como eu posso desmantelar meu próprio racismo?' e então esta pergunta por si só já inicia este processo $\mathbf{4 9 ( 1 8 0 ) .}$

Vimos, até aqui, o que as instituições e formas de pensar excluem e deixam de ver no Brasil, enquanto um Estado nacional moderno de origem colonial. Vimos corpos e territórios serem marcados, divididos, subalternizados, vulnerabilizados, destruídos... vimos a atualização disso e como é permanente em nossos dias. Vimos que a saúde e o campo da saúde coletiva, sendo parte desse Estado, não escapam desses traços nacionais, contribuindo para a invisibilização de estruturas que o sustentam.

Veremos, para concluir, que essas mesmas instituições, produzidas por humanos, são enfrentadas, se veem - com muito custo - e produzem formas de lidar com essa dinâmica moderna predatória e exclusiva, cujo tom intencionalmente enfatizamos aqui, justamente por ser o tom que prevalece. Noções como a de Democracia, Direitos Humanos e Ações Afirmativas emergem da luta contra a ação desse Estado racista e patriarcal e entram por ele, sendo assimiladas pelo próprio, tensionando-o. Há luta política; e o Estado cria formas de acomodá-la. Nesse processo de acomodação, dá-se visibilidade ao que foi excluído, e o grau de tensão torna-se crescente. Corpos que antes estavam excluídos não trazem apenas o seu corpo biológico para a arena política: trazem experiência, saberes, memória. Ao trazerem, colocam em xeque o próprio Estado, suas instituições e os corpos que se privilegiam da sua estrutura.

Como superar essa matriz exclusiva que sustenta os Estados nacionais modernos? Como seria um mundo sem essas estruturas institucionais? Quais instituições produziríamos e colocaríamos no seu lugar? Essas são perguntas que estão longe da nossa imaginação, quanto mais da nossa realidade política. Entendemos, contudo, que são perguntas que merecem ser perseguidas.

Quanto ao campo da saúde coletiva, como pode contribuir para perseguirmos as perguntas acima? Um caminho que sugerimos é: abertura e disposição a nos vermos, nos entendermos como corpos marcados e atravessados por dinâmicas estruturantes que beneficiam uns e excluem outros; e buscarmos a solidariedade. Retomando a introdução deste artigo, será um caminho tenso, doloroso e sem garantias. Mesmo entre os que estão dispostos a esse caminho, haverá aqueles que resistirão a se ver e a renunciar os privilégios. São décadas de saúde coletiva e séculos de Brasil em depuração, não será fácil... 


\section{Abaixo, trazemos cinco propostas para as nossas instituições:}

1. Apostar na política de cotas, ampliando a sua sensibilidade as marcas sociais e dinamicamente produzidas nos corpos e territórios pelo nosso Estado nacional. Com isso, teremos, frequentando a saúde coletiva, corpos políticos mais sensíveis aos problemas fundamentais da Saúde e do Brasil. Assim, poderemos contribuir para dar visibilidade a esses problemas, algo que, como campo de produção de conhecimento, devemos fazer.

2. Fazermos da política de cotas Ações efetivamente Afirmativas: não basta reservar vaga, mas permitir que os corpos políticos subalternizados possam concorrer às vagas, o que requer pensar as formas de acesso às nossas instituições. Depois que entram, esses corpos precisam permanecer nas nossas instituições. Para isso, eles devem poder frequentá-las e gozarem do que oferecem; portanto, precisam que necessidades básicas, como alimentação, moradia, o ir e o vir, estejam garantidas. Nossas instituições precisam estar mais que atentas a isso: precisam agir dentro das possibilidades para que a permanência e usufruto das suas estruturas aconteçam para todos os corpos que as frequentam, usando recursos de modo desigual para construir a igualdade de possibilidades. Não seria isso 'equidade'?

3. Produzidos o acesso e a permanência, é a hora de acolher o que esses corpos subalternizados 'falam', o que trazem de experiência e saber. Uma das operações mais nefastas e 'naturais' que a ciência moderna promove é desejar-se neutra, objetiva e formal, em seus conceitos e categorias. A vida deve ficar do lado de fora. Sabemos que isso é uma retórica a serviço do poder da ciência ocidental, e mesmo pessoas que fizeram ciência moderníssima por muitos anos, no ocidente, estão aí para corroborar o nosso argumento ${ }^{50,51}$. Construindo o olhar, os instrumentos e as formas do pensamento do cientista estão a vida, o território e o tempo em que vive, a sua própria experiência atravessada por muitas outras ${ }^{52}$. Colocar a experiência de vida como ponto de partida é a tarefa básica para quem quer conhecer. Experiências de vida diferentes levarão a caminhos diferentes, e precisamos nos organizar institucionalmente para percorrê-los.

4. Para percorrermos caminhos diferentes, precisaremos de ferramentas diferentes. Escrever a partir da vivência, do corpo, da experiência e da ancestralidade é trazer ao campo a produção de conhecimento situado $^{49}$, gerar brechas para o subalterno falar ${ }^{53}$ e possibilidades de moverem-se as estruturas $^{54}$. É preciso ter espaço para 'escreviver'55, como sugere Conceição Evaristo. O que pode ser feito por meio da escrita e de outras formas. Se temos tanta facilidade de incorporar gráficos, curvas, tabelas, por que não incorporamos outras formas de imagens? Para produzir conhecimento, é preciso ser sempre por escrito? E essa escrita precisa ser sempre formal, conceitual, categorial? Precisamos incluir corpos e ferramentas para expressar o que se sabe e se quer compartilhar. Nesse sentido, são necessários recursos analíticos que nos ajudem a superar a fragmentação da experiência e a segmentação das pautas políticas em uma contemporaneidade corporativa. Um exemplo de recurso analítico para nos fazer caminhar nesse sentido é a perspectiva interseccional ${ }^{56}$, que procura dar inteligibilidade às marcas de diferenciação nos corpos de modo articulado e dinâmico.

5. Para compartilharmos e dar visibilidade a tudo isto que queremos ver acontecer na saúde coletiva, é importante criar outras formas de difundir conhecimento além das revistas científicas e livros acadêmicos. Seguindo esse argumento, não podemos ser reféns da indústria publicacionista global que nos impõe formas e métricas de reconhecimento do que produzimos. Esse ponto 
é muito difícil de ser enfrentado, visto que estamos cercados por todos os lados, e as próprias instituições que fomentam o que fazemos as impõem como garantia. Somos lidos por essas formas e métricas. Porém, não podemos desistir de pensar e produzir em outros meios, especialmente naqueles de acesso aberto.

À luta!

\section{Referências}

1. Quijano A. Colonialidade do poder e classificação social. In: Santos BS, Meneses MP, organizadores. Epistemologias do Sul. São Paulo: Cortez; 2010 p. 84-130.

2. Fanon F. Pele Negra, Máscaras Brancas. Salvador: Edufba; 2008

3. Galeano E. As veias abertas da América Latina. Porto Alegre: L\&PM; 2016.

4. Quijano A. "Raza”, "etnia” y "nación” en Mariátegui: cuestiones abiertas. In: Quijano A. Cuestiones y horizonte: de la dependencia histórico-estructural a la colonialidad/descolonialidad del poder. Buenos Aires: Clacso; 2014. p. 757-777.

5. Ferrer A. A sociedade escravista cubana e a Revolução Haitiana. Almanack. 2012; (3):37-53.

6. Hobsbawn EJ. A era das revoluções. 9. ed. São Paulo: Paz e Terra; 1996.

7. Wallerstein I. A reestruturação capitalista e o sistema mundial. Perspectivas. 1997-1998; (20-21):249-267.

\section{Colaboradores}

Gonçalves LAP (0000-0002-6795-8374)*, Oliveira RG (0000-0001-8408-6427)*, Gadelha AGS (0000-0001-7767-4642)*, Medeiros TM (0000-0002-7679-0390)* contribuíram igualmente para a elaboração do manuscrito.
8. Gonçalves AM. Um defeito de cor. Rio de Janeiro: Record; 2006.

9. Reis JJ. Rebelião escrava no Brasil: a história do levante dos malês na Bahia em 1835. São Paulo: Companhia das Letras; 2003.

10. Silva DF. Oficina de imaginação política. "Sobre diferença sem separabilidade" [internet]. Portal issuu. 2016 set. [acesso em 2019 maio 31]. Disponível em: https: https://issuu.com/amilcarpacker/docs/denise_ferreira_da_silva_.

11. Mignolo WD. Colonialidade: o lado mais escuro da modernidade. Rev. bras. Ci. Soc. 2017; 32(94):e329402.

12. Fiori JLC. "Dialética da guerra e da paz: hierarquia, conflito e ética internacional" [internet]. Portal Instituto de Economia - UFRJ, 2017 [acesso em 2019 maio 31]. Disponível em: http://www.ie.ufrj.br/images/1_-artigo_guerra_e_etica_internacional_2_95b92.pdf.

13. Anzaldúa G. La conciencia de La Mestiza: rumo a uma nova consciência. Rev. Estud. Fem. 2005; 13(3):704-719. 
14. Lugones M. Rumo a um feminismo descolonial. Rev. Estud. Fem. 2014; 22(3):935-952.

15. McClintock A. "Pós-colonialismo e o anjo do progresso”. In: McClintock A. Couro Imperial: raça, gênero e sexualidade no embate colonial. Campinas: Unicamp; 2010. p.15-42.

16. Hall S. "Raça, o significante flutuante" [internet]. 1995. [acesso em 2019 set 15]. Disponível em: http:// revistazcultural.pacc.ufrj.br/raca-o-significante-flutuante\%EF\% $\% 0 \% \mathrm{AA} /$.

17. Gonzalez L. Racismo e Sexismo na Cultura Brasileira. In: Rev. Ciênc. Soc. Hoje. 1984; 223-244.

18. Silva DF. À brasileira: racialidade e a escrita de um desejo destrutivo. Rev. Estud. Fem. 2006; 14(1):61-83.

19. Camargo Jr KR. A biomedicina. Physis. 1997; 7(1):45-68.

20. Borghi CMSO, Oliveira RM, Sevalho G. Determinação ou Determinantes Sociais da Saúde: texto e contexto na América Latina. Trab. educ. saúde. 2018; 16(3):869-897.

21. Santos BS, Meneses MP, Nunes JA. "Introdução: para ampliar o cânone da ciência: a diversidade epistemológica do mundo”. In: Santos BS, organizador. Semear outras soluções: os caminhos da biodiversidade e dos conhecimentos rivais. Porto: Afrontamento, 2004.

22. Birman J. A Physis da Saúde Coletiva. Physis. 2005; 15(supl):11-16.

23. Alessi G. No Brasil, dois países: para negros, assassinatos crescem 23\%. Para brancos, caem 6,8\%. 2018 [internet]. Portal EL PAÍS jun. 17. [acesso em 2019 maio 31]. Disponível em: https://brasil.elpais.com/ brasil/2018/06/05/politica/1528201240_021277.html.

24. Arantes PE. 1964, o ano que não terminou. In: Teles E, Safatle V, organizadores. O que resta da ditadura: a exceção brasileira. São Paulo: Boitempo; 2010. p. 205-236.

25. Santos M. A Urbanização Brasileira. 3. ed. São Paulo: Hucitec; 1993.
26. Jesus CM. Quarto de despejo: diário de uma favelada. São Paulo: Francisco Alves; 1960.

27. Brum E. A Amazônia é o centro do mundo. Portal EL PAÍs [internet]. 2019. Ago 9. [acesso em 2019 set 9]. Disponível em: https://brasil.elpais.com/brasil/2019/08/09/opinion/1565386635_311270.html.

28. Nascimento A. O genocídio do negro brasileiro: processo de um racismo mascarado. Rio de Janeiro: Paz e Terra; 1978.

29. Cerqueira D, Lima RS, Bueno S, et al. Atlas da Violência 2018. Rio de Janeiro: Ipea; FBSP; 2018.

30. Mbembe A. Necropolítica, una revisión crítica. In: Chávez H, Ježikv E. Estética y Violencia: necropolítica, militarización y vidas lloradas, Museo Universitario Arte Contemporáneo. Cidade do México: Universidad Nacional Autónoma de México; 2012. p. 130-139.

31. Silva DF. Ninguém: direito, racialidade e violência. Meritum. 2014; 9(1):67-117.

32. Foucault M. Nascimento da Biopolítica: curso dado no College de France 1978-1979. São Paulo: Martins Fontes; 2008.

33. Lima F. Bio-necropolítica: diálogos entre Michel Foucault e Achille Mbembe. Arq. Brasil. Psicol. 2019; 70 (esp):20-33.

34. Coletivo Mariachi. O Fim do racismo será impossível sem o fim da branquitude, por Ronilso Pacheco [internet]. Portal Youtube 2017. [acesso em 2019 jun 2]. Disponível em: https://m.facebook.com/coletivomariachi/ photos/a.291536030986255/910059259133926/?type=3.

35. Gomes NL, Laborne AAP. Pedagogia da crueldade: racismo e extermínio da juventude negra. Educ. rev. 2018; 24(e197406):1527-1536.

36. Werneck J. Racismo institucional e saúde da população negra. Saude soc. 2016; 25(3):535-549.

37. Carneiro S. A batalha de Durban. Estud. Fem. 2002; 10(1):209-214. 
38. Gomes NL. O Movimento Negro educador - saberes construídos nas lutas por emancipação. Petrópolis: Vozes; 2017.

39. Munanga K. Uma abordagem conceitual das noções de raça, racismo, identidade e etnia. In: Brandão AAP, organizador. Programa de Educação Sobre o Negro na Sociedade Brasileira. Niterói: EdUFF; 2000. p. 15-34.

40. Congresso em Foco. A íntegra do manifesto contra as cotas raciais. Portal UOL, 2006. [acesso em 2019 set 15]. Disponível em: https://congressoemfoco.uol. com.br/especial/noticias/a-integra-do-manifesto-contra-as-cotas-raciais/.

41. Feres Júnior J, Daflon VT. A nata e as cotas raciais: genealogia de um argumento público. Opin. Publica. 2015; 21(2):238-267.

42. Brasil. Ministério da Saúde, Secretaria de Gestão Estratégica e Participativa. Política Nacional de Saúde Integral da População Negra: uma política para o SUS. 2. ed. Brasília, DF: Ministério da Saúde; 2013.

43. Brasil AS, Trad LAB. O movimento negro na construção da Política Nacional de Saúde Integral da População Negra e sua relação com o Estado brasileiro. In: Batista LE, Wernek J, Lopes F, et al, organizadores. Saúde da População Negra. Brasília, DF: ABPN, 2012. p. 62-91.

44. Ferreira JN. Promoção da igualdade racial em saúde: a constituição de uma política de saúde para a população negra [dissertação]. Porto Alegre: Universidade Federal do Rio Grande do Sul; 2016. 133 p.

45. Maio MC, Monteiro S, Rodrigues PHA. O SUS é racista? In: Fry P, Maggie Y, Maio MC, et al, organizadores. Divisões perigosas: políticas raciais no Brasil contemporâneo. Rio de Janeiro: Civilização Brasileira; 2007. p. 235-40.

46. Reis V. Conheça os três novos Grupos Temáticos da Abrasco [internet]. 2017. [acesso em 2019 maio 28]. Disponível em: https://www.abrasco.org.br/site/outras-noticias/institucional/conheca-os-tres-novos-grupos-tematicos-da-abrasco/29191/.
47. Batista LE. Porque a ABRASCO criou um GT Racismo e Saúde? Ensaios \& Diálogos em Saúde Coletiva. 2017 [acesso em 2019 maio 28]; (4):49-50. Disponível em: https://www.abrasco.org.br/site/wp-content/ uploads/2017/10/PDF_racismo_ensaios_4.pdf.

48. Faustino DM. A equidade racial nas políticas de saúde. In: Batista LE, Wernek J, Lopes F, et al., organizadores. Saúde da População Negra. Brasília, DF: ABPN, 2012. p. 62-114.

49. Grada K. A Máscara. Cadernos de Literatura em Tradução. (16):171-180, 2016.

50. Fleck L. Gênese e Desenvolvimento de um Fato Científico. Belo Horizonte: Fabrefactum; 2010.

51. Gould SJ. A falsa medida do Homem. São Paulo: Martins Fontes; 1999.

52. Haraway D. Situated knowledges: the science question in feminism and the privilege of partial perspective. Feminist Studies. 1988; 14(3):575-599.

53. Spivak GC. Pode o subalterno falar? Belo Horizonte: UFMG, 2010.

54. Davis A. Mulheres, raça e classe. São Paulo: Boitempo, 2016.

55. Evaristo C. Minha escrita é contaminada pela condição de mulher negra. Nexo. 2017. [acesso em $2020 \mathrm{fev}$ 21]. Disponível em: https://www.nexojornal.com.br/ entrevista/2017/05/26/Concei\%C3\%A7\%C3\%A3o-Evaristo-\%E2\%80\%98minha-escrita-\%C3\%A9-contaminada-pela-condi\%C3\%A7\%C3\%A3o-de-mulher-negra\%E2\%80\%99.

56. Akotirene C. O que é interseccionalidade? Belo Horizonte: Letramento; 2018. (Feminismos Plurais).

Recebido em 03/06/2019

Aprovado em 31/10/2019

Conflito de interesses: inexistente

Suporte financeiro: não houve 